The INL is a

U.S. Department of Energy

National Laboratory

operated by

Battelle Energy Alliance

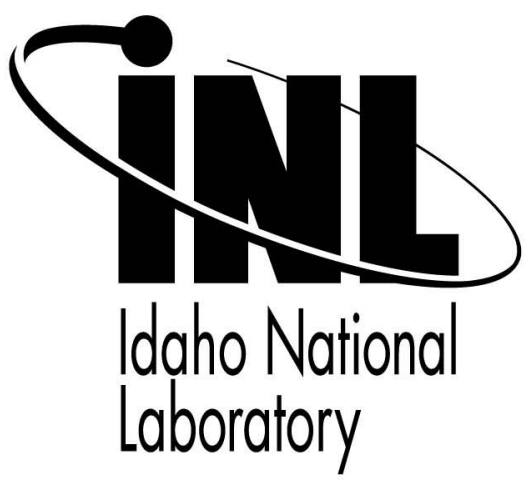

\section{Developing Multiple Diverse Potential Designs for Heat Transfer Utilizing Graph Based Evolutionary Algorithms}

\section{ASME 2006 International Design Engineering Technical Conferences and Computers and Information in Engineering Conference}

David J. Muth, Jr.

Daniel A. Ashlock

Douglas S. McCorkle

Kenneth M. Bryden

\section{September 2006}

This is a preprint of a paper intended for publication in a journal or proceedings. Since changes may be made before publication, this preprint should not be cited or reproduced without permission of the author. This document was prepared as an account of work sponsored by an agency of the United States Government. Neither the United States Government nor any agency thereof, or any of their employees, makes any warranty, expressed or implied, or assumes any legal liability or responsibility for any third party's use, or the results of such use, of any information, apparatus, product or process disclosed in this report, or represents that its use by such third party would not infringe privately owned rights. The views expressed in this paper are not necessarily those of the United States Government or the sponsoring agency. 


\section{Proceedings of IDETC/CIE 2006 \\ ASME 2006 International Design Engineering Technical Conferences \& \\ Computers and Information in Engineering Conference \\ September 10-13, 2006, Philadelphia, Pennsylvania, USA}

\section{DETC2006-99560}

\section{Developing Multiple Diverse Potential Designs for Heat Transfer Utilizing Graph Based Evolutionary Algorithms}

\author{
David J. Muth Jr. \\ Department of Mechanical Engineering \\ lowa State University \\ Ames, lowa 50011 \\ dmuthjr@iastate.edu \\ Daniel A. Ashlock \\ Department of Mathematics and Statistics \\ University of Guelph \\ Guelph, Ontario N1G 2R4 \\ dashlock@uoguelph.ca
}

\author{
Douglas S. McCorkle \\ Department of Mechanical Engineering \\ lowa State University \\ Ames, lowa 50011 \\ mccdo@iastate.edu \\ Kenneth M. Bryden \\ Department of Mechanical Engineering \\ lowa State University \\ Ames, lowa 50011 \\ kmbryden@iastate.edu
}

\begin{abstract}
This paper examines the use of graph based evolutionary algorithms (GBEAs) to find multiple acceptable solutions for heat transfer in engineering systems during the optimization process. GBEAs are a type of evolutionary algorithm (EA) in which a topology, or geography, is imposed on an evolving population of solutions. The rates at which solutions can spread within the population are controlled by the choice of topology. As in nature geography can be used to develop and sustain diversity within the solution population. Altering the choice of graph can create a more or less diverse population of potential solutions. The choice of graph can also affect the convergence rate for the EA and the number of mating events required for convergence. The engineering system examined in this paper is a biomass fueled cookstove used in developing nations for household cooking. In this cookstove wood is combusted in a small combustion chamber and the resulting hot gases are utilized to heat the stove's cooking surface. The spatial temperature profile of the cooking surface is determined by a series of baffles that direct the flow of hot gases. The optimization goal is to find baffle configurations that provide an even temperature distribution on the cooking surface. Often in engineering, the goal of optimization is not to find the single optimum solution but rather to identify a number of good
\end{abstract}

solutions that can be used as a starting point for detailed engineering design. Because of this a key aspect of evolutionary optimization is the diversity of the solutions found. The key conclusion in this paper is that GBEA's can be used to create multiple good solutions needed to support engineering design.

\section{INTRODUCTION}

Often optimization of a single analysis-based model is only one step in the engineering design process. Complete system design requires satisfying multiple constraints. These arise from several sources. These include 1) multiple models are often needed to support engineering design and 2) some criteria are implicit constraints that cannot be included in an analysis model (e.g. style, consumer usage). These constraints impact design as much or more than the design properties that can be explicitly optimized. For example, a successful design must be viable economically. These financial concerns are coupled with manufacturing and resource availability factors. The design process relies on finding a solution that satisfies all of these constraints. A particular concern within one area of analysis can often lead to unacceptable limitations on other criteria. For example, physical analysis of a system may require using a specific material in construction that is not currently available or economically viable. In these cases design is a process of 
compromise requiring that good solutions be used rather than the single best solution.

Because of this, an optimization process that creates a number of good diverse solutions is desirable. While this goal is achievable with evolutionary optimization, it is often at odds with the goal of creating a single optimal solution quickly. This occurs because often a good solution can quickly dominate an evolving population, eliminating acceptable solutions before they have a chance to mature. While these acceptable solutions may not evolve to become as good as the dominant solution, they can provide the additional opportunities essential for compromise within the design process. Multiple acceptable solutions to the optimization of an analysis model can lead to better solutions in the overall design problem.

This paper examines optimization techniques which preserve solution diversity in engineering design by placing a connection topology on the solution space. The topology, or geography, imposed on the population of solutions comes from the implementation of a type of evolutionary algorithm called graph based evolutionary algorithms. The diversity of natural populations demonstrate that geography can develop and sustain diversity in a population. Applying this concept to engineering design problems offers control over the diversity of possible solutions, potentially creating multiple acceptable designs.

\section{BACKGROUND}

Evolutionary algorithms (EAs) [1] are robust and appealing as an optimization technique. EAs provide the ability to search the solution space with minimal user intervention and allow the user to search the space with less prior knowledge than other optimization techniques. These factors have led to an increase in the use of EAs for engineering design problems [2]. One key aspect of EA's in engineering design is the creation of multiple designs. A technique, using quality or entropy as a diversity index, has been used to create, diverse solution sets for the mechanical design problem optimizing speed reducers. By explicitly optimizing the index at each system-level iteration, the method obtains an estimate of the Pareto frontier with maximum diversity. [3]

\section{Graph based evolutionary algorithms}

Graph based evolutionary algorithms (GBEAs) utilize combinatorial graphs to control interaction between members of an evolving solution set. The combinatorial graph acts as a geography placed on the solution set. This limits the mating pool for each population member which, in turn, reduces the transmission rate of information in the evolving population. Combinatorial graphs are described in [4]. The graphs can vary greatly in connectivity. Connectivity, in turn, controls how many potential mates are available for each individual in the population. In standard EAs, evolved solutions converge to have the same characteristics very quickly. Population members with low fitness, but useful sub-structures, can be lost early in the evolutionary process. By limiting the information spread within the population, the strong characteristics present in weak members can survive and be passed on to the rest of the population. Using graphs to control the rate of information spread can preserve diversity in the solution set giving many acceptable solutions.

\section{Optimization of thermal systems}

Optimization is a particular challenge for those thermal/fluid system problems in which the fitness function needs to be determined from high fidelity modeling (e.g. CFD) because of the lengthy compute time needed for most CFD analyses. This is particularly true for evolutionary optimization because of the number of fitness function evaluations required. Many projects have utilized thermal and fluids systems EAs in conjunction with high fidelity models to optimize engineering systems. Several applications coupling EAs and CFD have been found in aerodynamics. Airfoils [5, 6], diffusers [7], turbomachines [8], and compressors [9] are examples. These techniques have also been applied to three-dimensional shape optimization [10], sailing yacht fin keels [11], and stoves [12, $13,14]$. Using high fidelity models in conjunction with EAs exacerbates the issue of high computational expense associated with these models. EAs require many fitness calls during the evolution process with each call requiring the compute time of the high fidelity model.

Several techniques have been employed to deal with computational cost in using high fidelity models to perform fitness evaluation. Designs can be evolved using a low-detail representation of the system in question with the high fidelity model utilized in validation and refinement of the solution [15]. Other attempts to deal with this issue have been to use reduced forms of the three-dimensional Navier Stokes equations $[16,17$, $18]$, simplify the problem from three to two dimensions $[18,19$, $20,21]$, or use hybrid solver techniques [15, 19, 22]. Another approach has been to use graph based evolutionary algorithms (GBEAs) [12, 13, 14].

A novel technique $[12,14]$ simultaneously implementing GBEAs and real time estimates of final fitness and error bounds has been used in optimizing biomass cookstove design. The final fitness estimates were obtained from a universal approximator consisting of an artificial neural network (ANN) coupled with a feature weighted general regression neural network (GRNN) [22]. Four different graphs were used in this study: the 32-cycle, the (16,3)-Peterson graph, the $8 \times 4$ torus, and the five-dimensional hypercube. These graphs are described in full detail in [12]. The universal appoximator used a computationally inductive learning algorithm to establish the predicted final fitness value at each iteration of the CFD solver. At each mating event, fitness values were stored as a function of iteration in a growing database. The CFD iteration process was continued until the member winning the roulette selection process and having fitness greater than all other members within the tournament group were probabilistically equivalent. Fig. 1 represents the general structure of the revised algorithm used in this previous study. This is the methodology used in this study. 

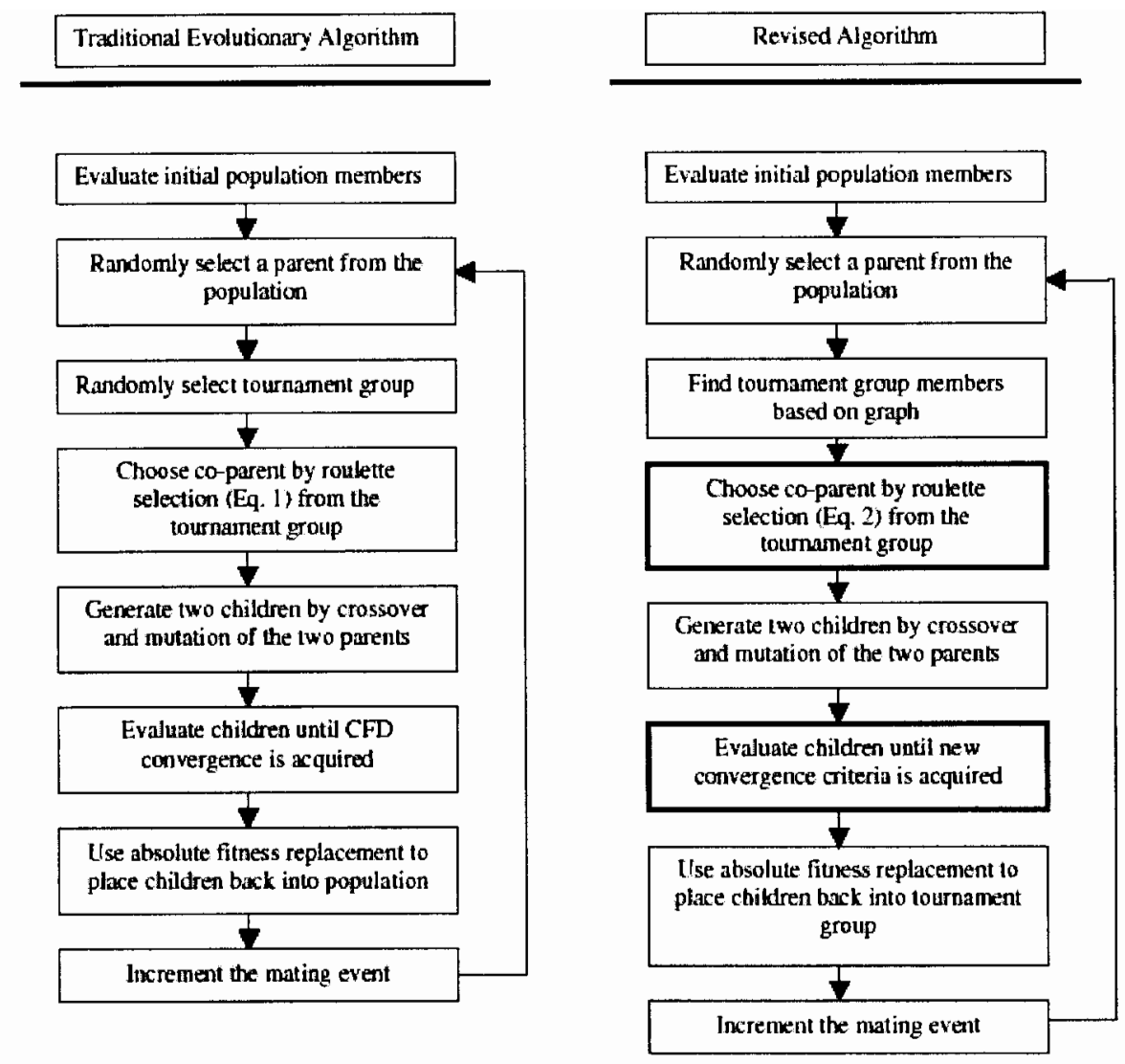

Figure 1: EA Flowchart

\section{DESIGN PROBLEM}

The design problem examined in this paper is the optimization of the spatial temperature distribution on biomass cookstoves being designed for use in developing nations. As shown in Fig. 2 this stove has three major components. These are 1) a small combustion chamber, 2) the baffled heat transfer chamber under the cooking surface, and 3) the chimney. The specific size and shape of the cooking service/heat transfer chamber varies depending on local needs and customs. There are several factors that need to be considered in addition to uniformity of the temperature of the stove surface during the design process. These include fuel consumption, manufacturability, cost, and ease of cleaning.

In developing nations household energy has significant health and economic impacts. In many cases indoor open fires are used for cooking and heating. These ad hoc cook fires are fuel inefficient, unsafe, and create significant health problems. For example many experts believe that 10 million women and children in Africa will die as a result of exposure to smoke from household cooking. One apparent solution to this problem is the

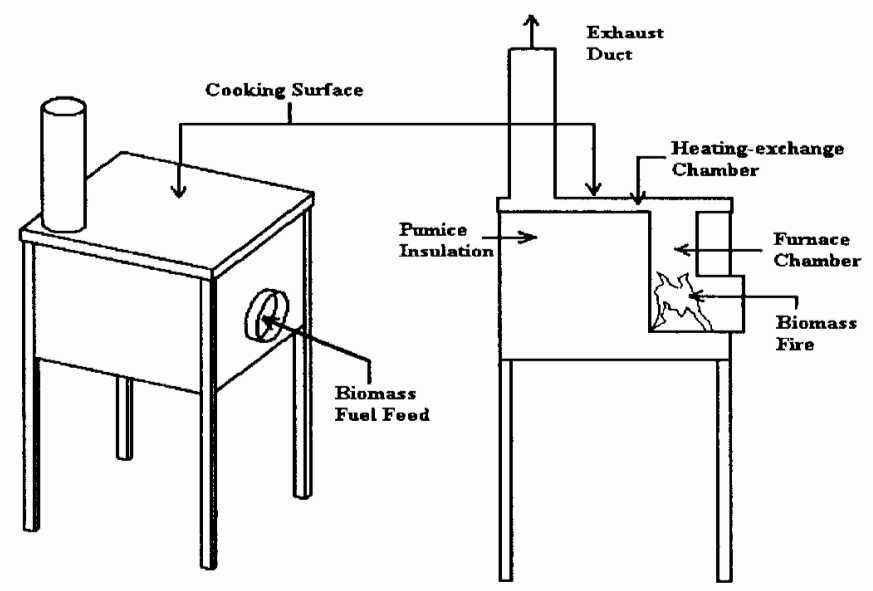

Figure 2: Basic Biomass Cookstove Design

development of inexpensive, locally manufacturable cookstoves that remove smoke from the house. Another key issue in cookstove design is the reduction of $\mathrm{CO}$ concentrations. Some homes where open flames were used for cooking were found to have $\mathrm{CO}$ levels as high as $160 \mathrm{ppm}$. Along with reducing $\mathrm{CO}$ concentrations, stove design optimization can significantly reduce the amount of firewood consumed and can help keep the 
fire away from children. Other health problems associated with current stove designs include infant mortality, blindness in women, and cancer $[24,25,26,27]$.

Another common issue with biomass cookstoves is a highly uneven temperature distribution across the cooking surface [13]. Engineering analysis in the field has shown that adding baffles to the flow field can redirect the flue gas flow and help eliminate large temperature variations across the cooking surface. Attempts to intuitively place baffles were unsuccessful in creating an ideal temperature distribution. This ideal distribution would have a single hot spot available for boiling water with a majority of the cooking surface operating at a relatively even temperature and possibly one small cooler region to keep fully-cooked products warm until full preparation is complete.

As stated previously, fuel consumption, manufacturability, cost, and ease of cleaning are also important design considerations for biomass cookstoves. Some of these factors are subjective and highly variable for individual stove designs. Making design decisions on these variables then often requires human expertise and intuition. In order to support these issues this work seeks to produce multiple optimized designs, in terms of heat transfer to the cooking surface, which can then be the starting place for the final design process. These needs make biomass cookstove design a unique and valuable application for the use of GBEA's. As described previously, the inherent structure of GBEA's facilitates the preservation of diversity in solutions. The biomass cookstoves application utilizes these internal characteristics in order to mathematically evaluative objective design variables. Then a decision maker can work with multiple good solutions in order to more effectively satisfy subjective design criteria.

\section{COMPUTATIONAL METHODOLOGY}

In this study the airflow and heat transfer analysis within the cookstove is performed with a commercial software package, Star-CD ${ }^{\mathrm{TM}}$. Given the complexity of the flow field, a high fidelity CFD model is needed to predict the surface temperature of the stove. The CFD analysis is run to evaluate fitness for each proposed baffle design. The heat exchange chamber is modeled as a simple rectangular prism coupled with the combustion chamber and exhaust duct. In-field measurements are used in determining the boundary conditions for the model. The boundary conditions at the inlet of the heat transfer chamber during typical cooking parameters are measured and used in place of a combustion model. Inlet velocity is set at $3.88 \mathrm{~m} / \mathrm{s}$ and temperature at the inlet is set at $977 \mathrm{~K}$. The impact on air density from changing temperatures is modeled. A $\mathrm{K}-\epsilon$ model with an intensity of 0.1 and entrance length of $4.8 \mathrm{~cm}$ is used to model turbulence. Resistance to heat transfer from the cooking surface is modeled using a surface thickness of $1.6 \mathrm{~cm}$, a heat transfer coefficient of $20 \mathrm{~W} / \mathrm{m} 2 \cdot \mathrm{K}$, and a thermal conductivity of $30 \mathrm{~W} / \mathrm{m} \cdot \mathrm{K}$. Simulating the pumice insulation commonly used in stove construction, the remaining surfaces are modeled to be adiabatic. Using these conditions a single CFD evaluation converges to a solution in under 2 minutes on cluster nodes of a Red Hat Enterprise Linux machine running $1.2 \mathrm{GHz}$ processors with $1 \mathrm{~GB}$ of memory.

The GBEA used to create the stove designs evolves 32 randomly selected stove structures via mutation and crossover operations. Fitness is defined as a percent of usable area on the cooking surface where surface temperature, $T_{i}$, is assessed at all surface points other than those directly above the combustion chamber and below the chimney, and $T_{a v g}$ is taken as the average of $T_{i}$. Each $T_{i}$ is then tested within an interval of $T_{\text {avg }}$ and surface points satisfying the criteria are categorized as usable area. The fitness function then calculates the percent of usable area as a function of total cooking surface area. This study utilizes three different sets of fitness criteria in analyzing stove designs. One set required each $T_{i}$ to be within an interval of $+/-25^{\circ} \mathrm{C}$ of $T_{\text {avg }}$ in order to be categorized as usable area. Fitness is also measured with intervals of $+/-50^{\circ} \mathrm{C}$ and $+/-75^{\circ} \mathrm{C}$.

Four operations are performed in each mating event. Selection, crossover, mutation, and replacement operators are employed at each generation. Selection is done by selecting one parent randomly from the population and then selecting a coparent with roulette selection. Once the parents were chosen, crossover and mutation operations are used to create two children. The crossover operator used is a single point crossover (Fig 3.). Two types of mutation are used to evolve the

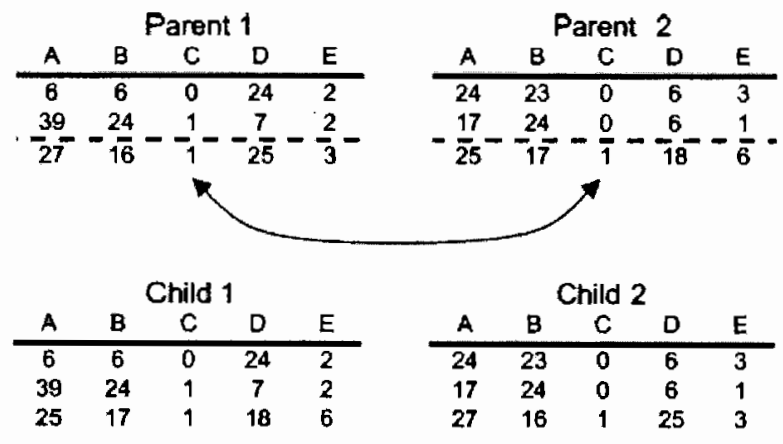

Figure 3: Crossover Operations

baffles. A single point mutation is used where a baffle is randomly chosen and a single integer parameter defining that baffle is randomly selected and changed to a new value, also selected at random. The second mutation operator is list mutation, which randomly selects a baffle and replaces that baffle with a new one. The inlet and outlet locations are evolved with a single point mutation operator. Preliminary experimentation demonstrated a need to reduce the impact of mutation on the population as evolution proceeded into later generations. The complexity of the fitness landscape caused highly evolved solutions to drastically lose fitness with small genetic modifications. To combat this effect mutation rate was probabilistically decreased as the generations of evolution 
proceeded. Early in evolution the effects of mutation are valuable in allowing the population to investigate the entire search space, but as the evolved population approaches optima, mutations often cause significant losses in fitness.

Work utilizing the previously described optimization routine has been done to create optimized plancha stove designs $[12,13,14]$. The improved plancha stove was developed to address the many health and efficiency concerns mentioned previously. While the improved plancha stove successfully dealt with many of these concerns, the temperature profile on the cooking surface was highly uneven (Fig. 4).
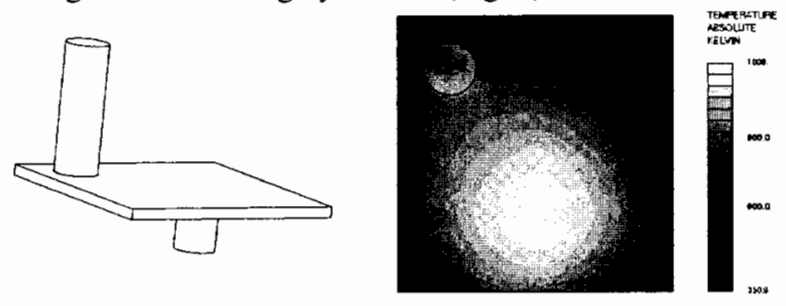

Figure 4: Unbaffled Plancha Stove (temperature scale from 350 to 1000 Kelvin)

The heat exchange chamber for this stove is modeled as a rectangular prism of $54 \mathrm{~cm} \times 54 \mathrm{~cm} \times 2.5 \mathrm{~cm}$, representing the square cooking surface of the plancha stove. The optimized plancha stove designs created a more ideal temperature profile by moving the inlet and outlet and placing baffles in the flow field (Fig. 5). The

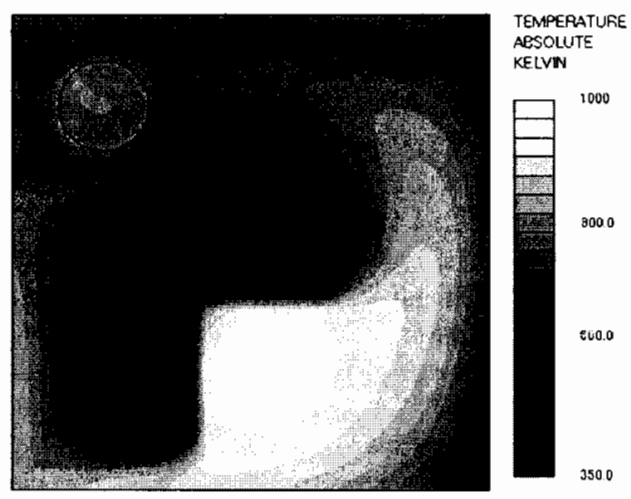

Figure 5: Baffled Plancha Stove

current analysis looks at plancha stove optimization from the perspective of attaining multiple good solutions.

Two variations of the Onil stove are also analyzed for this study. Health and efficiency concerns were again a key motivating factor in the development of this stove. The Onil stove, like the plancha stove, is modeled as a heat exchange chamber coupled with an inlet from the combustion chamber and an exhaust outlet. Also like the plancha stove, the Onil stove has an uneven temperature profile on the cooking surface.
Rectangular prisms of $81 \mathrm{~cm} \times 41 \mathrm{~cm} \times 2.5 \mathrm{~cm}$ and $61 \mathrm{~cm} \times 41$ $\mathrm{cm} \times 2.5 \mathrm{~cm}$ are used to model the Onil heat exchange chamber. These models create two variations of rectangular cooking surfaces, which, along with the square cooking surface of the plancha stove, are representative of the cookstoves found in many homes.

\section{RESULTS}

All three optimized stove geometries share the characteristic of positioning the outlet at a diagonal from the inlet. The rectangular shapes show a distinct preference for placing the inlet and outlet in opposite corners of the heat exchange chamber. This characteristic is highly dominant early in the evolutionary process, and in order to reduce computational expense, the Onil stove models are run with fixed inlet and outlet positions in opposite corners of the stove. As stated earlier, fitness is evaluated under three criteria: percentage of cooking surface area within $\pm 25^{\circ} \mathrm{C}, \pm 50^{\circ} \mathrm{C}$, and $\pm 75^{\circ} \mathrm{C}$ of the average surface temperature.

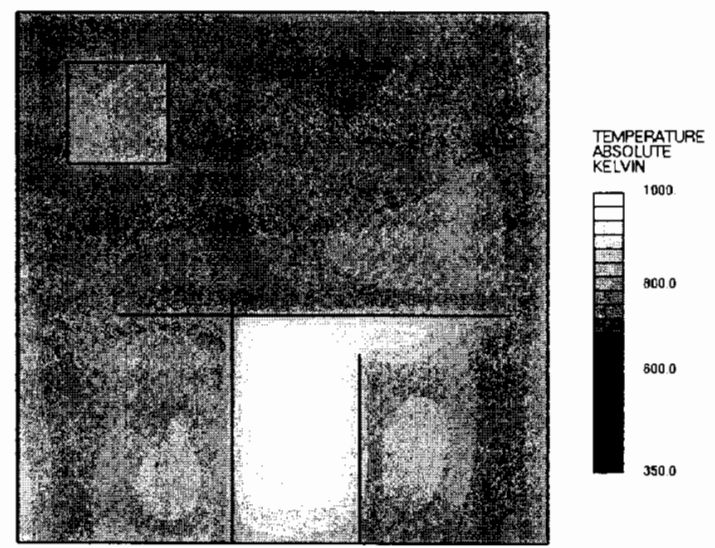

Figure 6: Common Baffle Structure

The optimized plancha stove models show significant improvements in the percentage of usable area on the cooking surface. Using a fitness measure of $\pm 25^{\circ} \mathrm{C}$, the unbaffled plancha stove demonstrates a fitness of less than $40 \%$. Several optimized designs are found to have $90 \%$ or more of the cooking surface satisfying the fitness criteria. Analysis of the optimized designs shows a clear pattern for the plancha stove model. The most prevalent design places three baffles closely surrounding the inlet, with one of the baffles running nearly the entire width of the stove between the inlet and outlet (Fig 6). This general pattern appears frequently as a rotation of 90 or 180 degrees of a previous design. Fig. 7 shows several highly fit plancha stove designs demonstrating different surface temperature profiles. With several stove designs satisfying the physical constraints, design decisions can then focus on usability, manufacturing and economic concerns, and materials availability. 

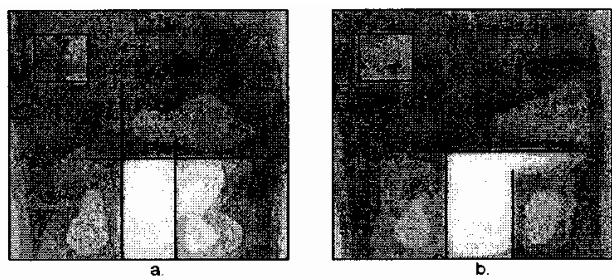

TEMPERATURE

(K)
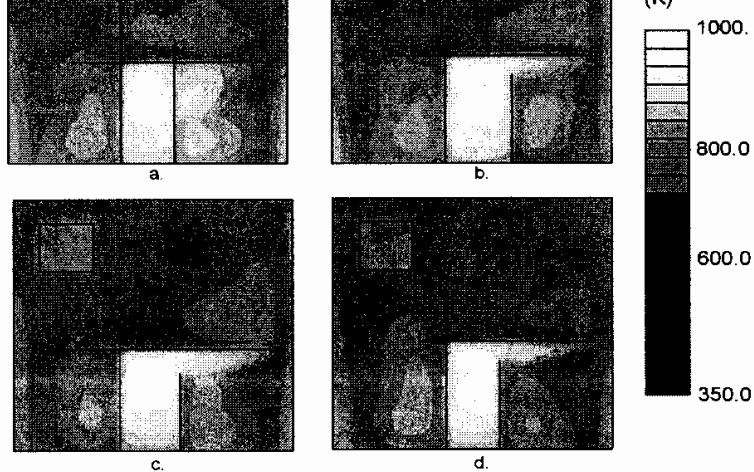

600.0

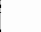

350.0

Figure 7: Multiple Temperature Profiles in Optimized Plancha Stoves

The population of Onil stove shapes also recognizes significant increases in the percentage of usable area on the cooking surface. The graph in Fig. 8 shows the increase in fitness for each of the three evaluation criteria for populations evolved on the four graphs versus the fitness of an unbaffled 81 $\mathrm{cm} \times 41 \mathrm{~cm} \times 2.5 \mathrm{~cm}$ Onil stove. Evaluation of the highly fit stoves demonstrates several unique baffle designs (Fig. 9). In many cases, the evolved designs create similar flow fields, but the variation in baffle layouts allows for other important factors, such as cost and manufacturing concerns, to help guide the design process. Because these stoves are built by hand in third world countries, where the tooling and jigs are very primitive, assembly considerations are a key component in establishing what constitutes a good design. This idea is clearly demonstrated in comparing the baffle configurations in Fig. 10, which shows three very different $61 \mathrm{~cm} \times 41 \mathrm{~cm} \times 2.5 \mathrm{~cm}$ onil stoves compared to an unbaffled stove with inlet and outlet positions in opposite comers. While both stoves are fit, the substantial differences in design can impact the cost, time, and ease of construction. For example, decreasing the number of intersections between baffles will offer a less complicated assembly process.

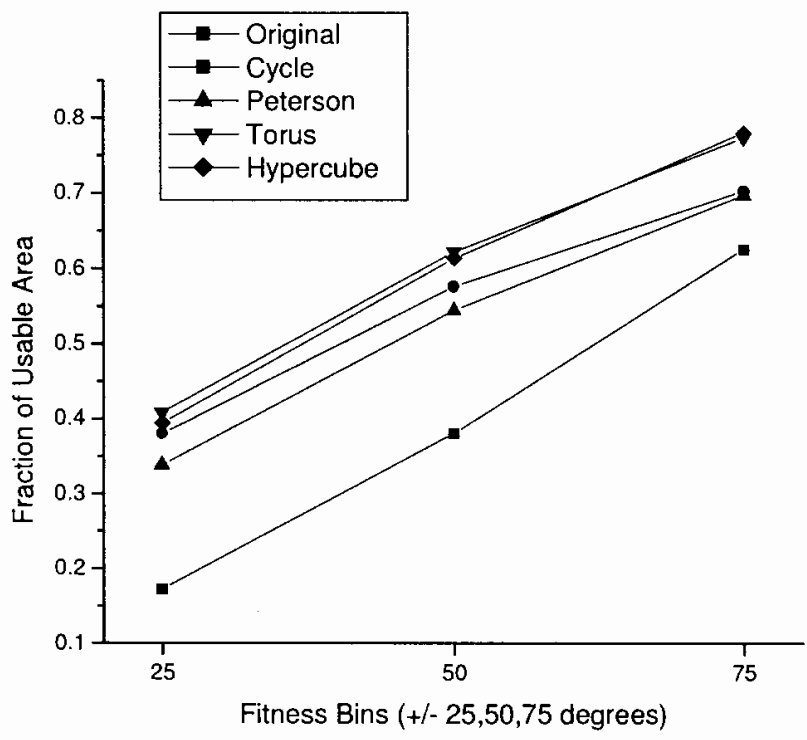

Figure 8: Usable Area for Each Graph and Each Fitness Bin Compared to the Original Onil Stove
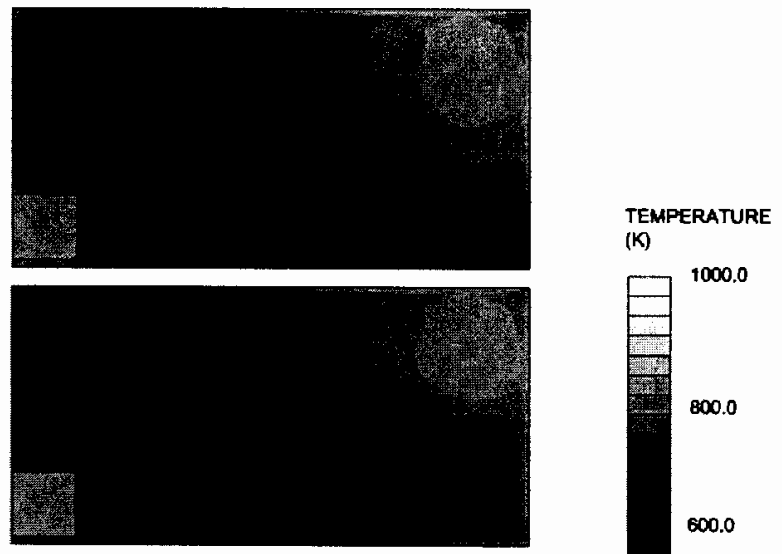

(K)
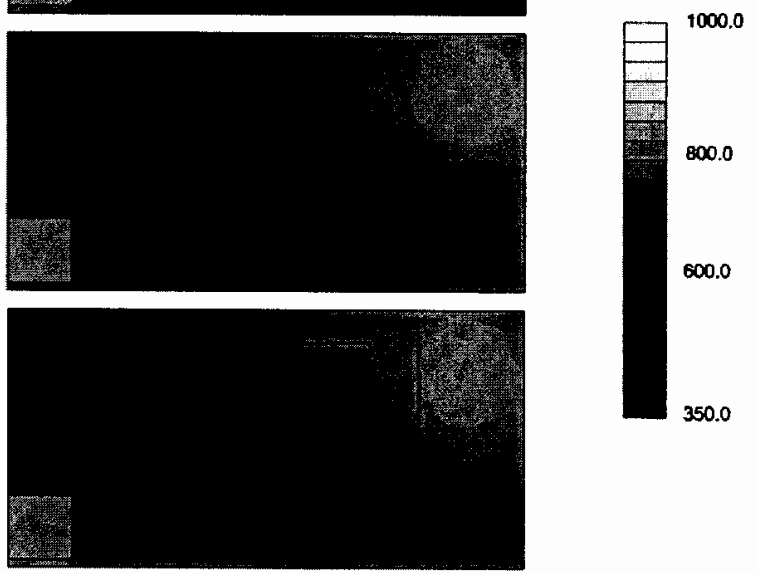

350.0

Figure 9: Several Fit, but Unique Onil Stove Designs 

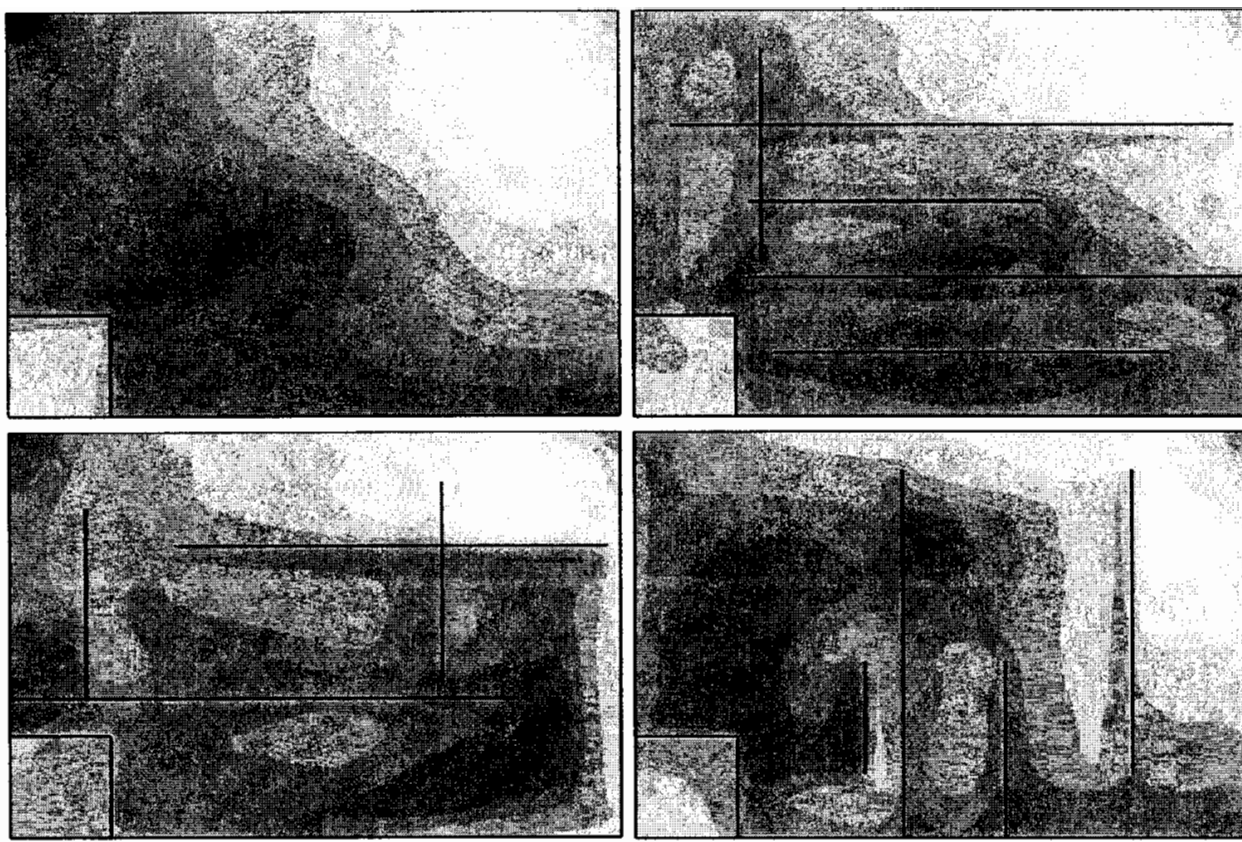

Temperature (K)

Figure 10: Unique Optimized Modified Onil Stoves Compared to Original Unbaffled

\section{CONCLUSIONS AND FUTURE WORK}

This paper presents an application of an optimization technique combining GBEAs and ANNs. GBEAs provide a means to maintain diversity in an evolving population. For this study, that characteristic is employed to find a diverse set of good designs for multiple stove shapes. The effectiveness of a design is measured as a percent of usable area on the cooking surface and is evaluated at three different temperature intervals. Several stove shapes are evaluated demonstrating the ability to create more even temperature profiles for many of the diverse shapes and configurations of stoves that may be found. This ability can provide a significant amount of valuable information to assist an engineer in analyzing design configurations for these stoves. A large set of good designs for several stove shapes can help build more efficient and safe stoves when faced with third-world construction constraints.

Future work in this area includes allowing an analyst to interactively build the stove in question and run the optimization algorithm in order to get several design options for that stove. Inefficient and flawed stove designs cause serious health risks. Extending studies such as this to evaluate existing stoves and explore new designs can provide useful information for making engineering decisions.

\section{ACKNOWLEDGMENTS}

We want to thank the following people and organizations for their help and support in this work: Dean Still and Nordica Hudelson at the Aprovecho Research Center and Stuart Conway with Trees, Water, and People.

\section{REFERENCES}

1. Goldberg DE. Genetic algorithms in search, optimization and machine learning. Reading:Addison-Wesley, 1989.

2. Parmee IC. Evolutionary and adaptive computing in engineering design. London: Springer-Verlag, 2001

3. Gunawan S, Farhang-Mehr A, Azarm S. On maximizing solution diversity in a multidisciplinary genetic algorithm for design optimization. Mechanics Based Design of Structures and Machines 2004:32:491-514

4. West D.B. Introduction to Graph Theory. Prentice Hall, 1996

5. Goel S, Hajela P. A classifiers based optimization technique for designing turbine airfoils. Engineering Optimization 2002;34;n3:195-218

6. Wang J, Yizhao W, Periaux J. Parallel hierarchical evolutionary algorithms for multicriteria design optimization problems in aerospace engineering. 44th AIAA/ASME/ASCE/AHS/ASC Structures, Structural Dynamics, and Materials Conference 2003;4:2678-2685.

7. Benini E, Toffolo A. Centrifugal compressor of a $100 \mathrm{~kW}$ microturbine: Part 3 - Optimization of diffuser apparatus. 2003 ASME Turbo Expo 2003;3:707-714.

8. Oyama A, Liou MS. Design optimizations of turbomachines using evolutionary algorithm. The Aeronautical and Astronautical Society of the Republic of China 2002;2:87-102.

9. Benini E, Toffolo A.Towards a reduction of compressor blade dynamic loading by means of rotor-stator interaction 
optimization. Proceedings of the ASME TURBO EXPO 2002;5A:667-674.

10. Foster GF, Dulikravich GS. Three-dimensional aerodynamic shape optimization and gradient search algorithms. J Spacecraft Rockets 1997;34:36-42.

11. Poloni C, Giurgevich A, Onesti L, Pediroda V. Hybridization of a multi-objective genetic algorithm, a neural network and a classical optimizer for a complex design problem in fluid dynamics. Comput Methods Appl Mech Eng 2000;186:403-420.

12. McCorkle DS, Bryden KM, Carmichael CG. A new methodology for evolutionary optimization of energy systems. Comput Methods Appl Mech Eng 2003;192: 5021-5036

13. Bryden KM, Ashlock DA, McCorkle DS, Urban GL. Optimization of heat transfer utilizing graph based evolutionary algorithms. Int J Heat Fluid Flow 2003;24: 267-277.

14. Bryden KM, McCorkle DS. Evolutionary optimization of energy systems using population graphing and neural networks. Submitted for publication.

15. Zha G, Smith D, Schwabacher M, Rasheed K, Gelsey A, Knight D, Haas M. High performance supersonic missile inlet design using automated optimization. J Aircr 1997;34:697-705.

16. Blaize M, Knight D, Rasheed K. Automated optimal design of two-dimensional supersonic missile inlets. J Propul Power 1998;14:890-898.

17. Mäkinen R, Periaux J, Toivanen J. Multidisciplinary shape optimization in aerodynamics and electromagnetics using genetic algorithms. Int J Numer Methods 1999;30:145-159.
18. Schmit TS, Dhingra AK, Landis F, Kojasoy G. Genetic algorithm optimization technique for compact high intensity cooler design. $\mathrm{J}$ Enhanced Heat Transfer, 1996;3:281-290.

19. Fabbri G. Optimization of heat transfer through finned dissipators cooled by laminar flow. Int $\mathbf{J}$ Heat Fluid Flow 1998;19:644-654.

20. Trigg MA, Tubby GR, Sheard AG. Automatic genetic optimization approach to two dimensional blade profile design for steam turbines. Trans ASME Turbomachinery 1999;121:11-17.

21. Fan HY. Inverse design method of diffuser blades by genetic algorithms. Proc Inst Mech Eng Part A 1998;212:261-268.

22. Quagliarella D, Vicini A. Viscous single and multicomponent airfoil design with genetic algorithms. Finite Elem Anal Des 2001;37:365-380.

23. Specht DF. A general regression neural network. IEEE Trans. Neural Networks 2 1991: 525-533.

24. Instituto Nicaragüense de Energia (INE). Memoria INE 1997. Managua, Nicaragua, 1997.

25. Hong CJ. Health Aspects of Domestic Use of Biomass Fuels and Coal in China. Shanghai: Shanghai Medical University, 1994.

26. Barnes D, Openshaw $K$, Smith $K R$, van der Plas $R$. What makes people cook with improved biomass stoves?. World Bank Technical Paper: Energy Series 242 1994;242:1 -39.

27. Pandey M.Health risks caused by domestic smoke. Boiling Point 1998;40:6 -8.

28. "In Africa, Lifting the Pall of Smoke From Cooking," by Susan P. Williams, Washington Post, 23 May 2005, p. A7. 